\title{
LOGISTICS SUPPORT OF RESOLUTE SUPPORT MISSION
}

\author{
Col Slobodan CURCIJA, M.Sc. \\ Croatian Defence Academy "Petar Zrinski"
}

\section{Summary}

The Resolute Support Mission (RS) is the extension to the completion of ISAF operations. It is expected to start on 1 January 2015.

NATO member states as well as troop contributing nations' units are entering a completely different situation compared to the current course of the mission. The RS mission is based on different assumptions including the drastic scaling down of the military presence in the area of operation. The main focus is shifting from combat operations to training, advice and assistance to the Afghan National Security Forces. Also, a very important role will be given to advisory and assistance support for the Afghan Security Institutions, primarily at the ministerial level in the Ministry of Defense, Ministry of Interior and the National Directorate of Security.

Logistics capability to support this type of military operation is fundamental for ensuring the success of the mission. Clear roles for all participants in the supply chain will require not only the necessary international support, but also the internal logistical connection.

The classical military logistical support will be replaced by some, so far, less applied models. Furthermore, the plan is to increase the use of multinational logistics agreements, the joint logistics support group, commercial contracts and the support capabilities of the host nation.

The logistics organisation designed in this way will represent a major challenge for its implementation in practice.

Key words: Mission, concept, logistics, support 


\section{Introduction}

The Resolute Support (RS) mission is planned as an extension of ISAF operations but on completely different foundations. ISAF, having been primarily a combat and counter-terrorism mission, along with operations against the illegal production of narcotics, sees its focus now shifted to training, advising and assisting (TAA). These activities are crucial for the achievement of NATO's end state which means the Government of the Islamic Republic of Afghanistan is responsible for the implementation of security in a sustainable manner. TAA activities will be conducted at the level of security ministries and national institutions (including the National Headquarters of the Armed Forces, the Command of the police forces, the National Defence Academy, Afghan security ministries, national logistics centres and training institutions). The advisory role will carried out only at the corps level and the level of police zones. Special operations forces will be trained, advised and assisted at all levels (including tactical) in order to develop the full range of capabilities for the implementation of special operations.

Logistic support for the RS operation will require the application of different solutions than was the case with the ISAF operation. The strategic logistics priority is maintaining an effective and efficient logistics system capable of accomplishing the best possible support in the RS. Furthermore, the plan is to increase the use of multinational logistics agreements, the joint logistics support group (JLSG), commercial contracts and the support capabilities of the host nation.

Nations are encouraged to use the NATO Support Agency (NSPA) which can develop contracts for the entire operation. Responsibility for the planning and management of deployment, redeployment and providing support (including medical support for joint forces and operational partners) remains national. Cooperation and coordination of logistics support between NATO and its partners will be implemented at the appropriate levels. Nations participating in the operation are advised to use logistics solutions that have already been applied in the area of operation. NATO standards of logistic supply will need to be applied to NATO and non NATO members in the RS in order to reduce the logistical presence in the area of operations but also to reduce the costs associated with insurance of stocks. Logistical requirements need to suggest the close cooperation 
of all involved military levels, the nations and partners, the Government of the Islamic Republic of Afghanistan (GIRoA), multinationals and solutions established through civilian contractors.

\section{Logistics concept in Resolute Support}

The logistics concept in the RS mission is designed as a combination of national, multinational and contractual solutions.

This concept is based on the role of Framework Nation (FN), the Joint Logistic Support Group, the Basing Operating Cell (BOC) and support through civilian capacity or contracted civilian support.

\section{Framework Nation}

In accordance with NATO's logistics doctrine, the nations can accept responsibility or be appointed responsible for the procurement and provision of a wide range of logistic support for all or a part of the units and headquarters. A nation that takes responsibility is called the framework nation.

For the purposes of the RS, the framework nation will assume overall responsibility for the coordination and implementation of the agreed range of logistic support for all or a part of the multinational forces, including commands within specific regions in Afghanistan. Framework nation has responsibility for the security of real life support (RLS) for national contingents operating with their specific locations. As a prerequisite, it is necessary to conclude bilateral agreements and resolve issues such as activities related to finance, contracts, property and legal security. For example, if the German Armed Forces take over the role of the framework nation in Northern Afghanistan, it would in practice result in the conclusion of the Memorandum of Understanding between the framework nation and nations participating in the operation. In addition, if the nations participating in the operation plan to rotate their national contingents in the Afghanistan joint area of operations in order to acquire the status of supported nation, they will 
have to develop separate technical agreements with the Framework nation for the provision of logistic support, in this case this being the Bundeswehr. Thesetechnical agreements will precisely regulate the implementation of real life support, services and procurement of goods in the operation and financing costs. In general, the level of service that is carried out should not be less than the framework nation provides it for its own forces. Moreover, it must be in accordance with existing standardised agreements. Thus, it is anticipated that the quality standards yet to be met should be based on existing standardised agreements, such as STANAG 2034 - NATO standard procedures for mutual logistical support.

\section{Basing Operating Cell}

The Basing Operating Cell (BOC) is a coordinating element that connects each location with the Joint Logistic Support Group (JLSG). Ideally, the BOC will manage providing logistical support by assets of National Support Elements (NSE) which will contribute to reducing the personnel in the field.

\section{Joint Logistic Support Group (JLSG)}

The development of the NATO operational deployment and the need for the best use of limited logistical resources together with increased participation of partner countries in NATO operations resulted in the development of the different concepts of support. Here, substantial emphasis is given to a multinational approach to the organisation and implementation of logistics. The NATO concept of the operation implementation clearly indicated the role of new elements of logistics support. The accent is on planning, coordinating, and executing the logistical support of nations that participate in the operation. Thus, the NATO Response Force (NRF), in addition to logistics organic units, also has a JLSG planned and structured to coordinate multinational logistics elements.

The NATO KFOR (Kosovo Forces) established command JLSG which, in addition to staff organisation, has multinational unit elements. 
NATO's new concept JLSG was tested in April 2012 during the preparation of the joint German-Dutch Corps. Attention was, in particular, paid to the ability to merge soldiers, equipment and continuation of movement. Instead of forming units after their arrival in individual international bases, the option to merge soldiers and their equipment in deployable forces immediately after their arrival at airports and ports, followed by their movement toward operating bases, was discussed.

The main idea of the multinational logistic exercise "Capable Logistician" conducted in 2013 in the Slovak Republic was planning logistics support and training interoperability through several logistics functions. JLSG function is established and tested in field conditions.

In accordance with NATO doctrine, JLSG HQ will be deployed to the joint operation area in order to plan, coordinate and facilitate the execution of multinational logistics support in coordination with the National Support Elements. JLSG HQ will use a combination of assigned national, civilian and host nation capabilities in order to provide the required level of multinational support in the joint operation area. The fundamental role of JLSG implies coordination and execution of multinational logistics support in accordance with the plans and guidelines of the Joint Forces Command, using the assigned resources.

JLSG tasks include the following:

- Provides support and advice to the staff of the Joint Task Forces HQ (JTF HQ) during the operational planning process, including the development of the logistics concept of operation

- Ensures staff that fill liaison and reconnaissance team in operations

- In cooperation with personnel from staff support element (DCOS SPT), identifies options for multinational logistic support

- Coordinates and executes logistics support of the joint operational area in accordance with the JTF HQ logistical plan, and in cooperation with nations (reception, merge soldiers and equipment, continuation of movement, fuel supply, common stock and services, etc.)

- Commands and coordinates assigned national, commercial and host nation resources

- Trains and integrates staff planned to fill JLSG HQ for operations and exercises 
- Establishes the required support and facilities to ensure the efficient and effective reception, merging of soldiers and equipment and continuation of movement

- Coordinates logistic support in close cooperation with nations

- Coordinates logistic support of the host nation

- Manages the transport operations in the joint operation area

- Coordinates and executes NATO funded contracts

- Coordinates the process of contracting with the NATO Support Agency (NSPA), host nation and nations

- Plans, prepares and organises the augmentation of JLSG HQ

- Ensures liaison officers for the appropriate command

- Receives and supports liaison officers from the respective headquarters and national support elements

- Helps in terms of training and mentoring the associated part of JLSG HQ

- Helps in the certification of the associated part of the JLSG HQ

- Provides advice to the staff from the superior command of the JLSG capabilities and operations if requested

- Maintains assigned NATO logistics information systems and related logistics data

- Contributes to the development of NATO logistics doctrine and concepts

- Contributes to the development of NATO logistics information system and software

- Contributes to the modifications of the standard operating procedure (SOP) for JLSG HQ

- Contributes to the creation, development and implementation of new NATO logistics capabilities

- Provides staff to support training and exercises in the Joint Warfare Centre (JWC) if requested

- Provides staff to support logistic courses at the NATO School in Oberammergau

- Contributes to the tasks of military cooperation and support of NATO programmes for the evaluation

- Contributes to the training and exercises with partners if it requires higherlevel command 
The JLSG Structure is directed towards the mission and the implementation of small or major joint operations (SJO - Small Joint Operations; MJO - Major Joint Operations)

A few basic guidelines can be mentioned here (AJP-4.6 (B), Allied Joint Doctrine for the Joint Logistic Support Group, Study Draft, 2011):

- JLSG is set to accomplish a task, which its component parts confirm as well, e.g. Reception, Staging Onward Movement (RSOM), movement and transportation, supply classes of material and others.

- Flexibility in terms of planning, coordination, command and execution

- Deployability in the area of operations

- Structure agreed with the nations during the operational planning process

- Multinational and commercial dimensions

JLSG can be set as an organisational element of the C2 system. In this case, it is commanded by the JLSG commander who is within the system of command and control of the operation. In a case where JLSG is set as a C2 system element, it develops certain units enabling its commander to coordinate and implement logistics support. On the other hand, JLSG can be set as a staff element operating within the Combined Joint Logistics (CJ4). Its primary task, then, is to coordinate logistics support at different levels.

JLSG general structure as a C2 system element includes the following units:

- In support of command (civil-military cooperation, public relations and communication and information systems)

- Classes of supply (class I, III, V and water)

- Movement and transportation

- General Engineers

- Medical Support

- Protection Force 


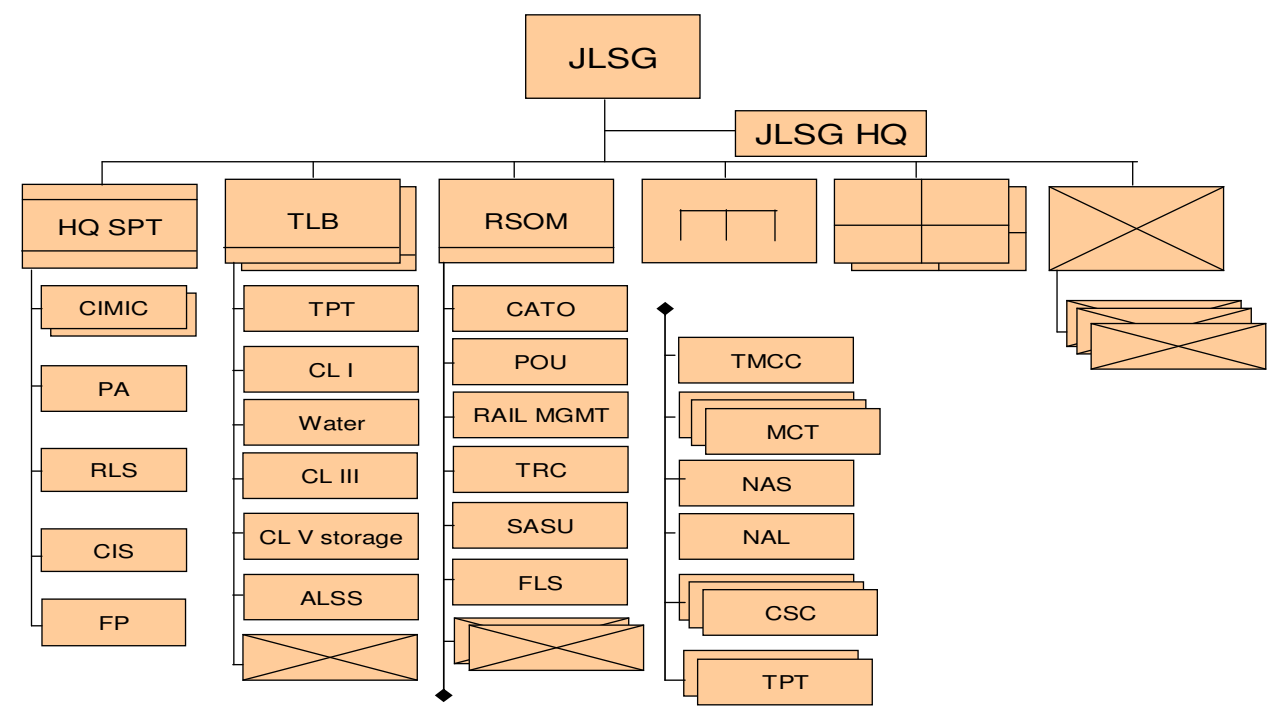

Source: AJP-4.6 (B), 2011, Allied Joint Doctrine for the Joint Logistic Support Group, Study Draft, Brussels, NATO.

\section{Scheme 1: The general structure of JLSG with units}

\section{General structure of JLSG Command}

General structure of JLSG Command includes the following positions:

- Logistics personnel - 4

- Logistics operations and plans - 8

- Movement and transportation - 3

- Personnel staff - 1

- Operational planning staff - 2

- Communication and information staff - 1

- Medical staff - 1

- Joint engineer staff - 2

- Finance staff - 1

- Civil-military cooperation staff - 1

In Total: 25 people (this number can be reviewed and modified) 


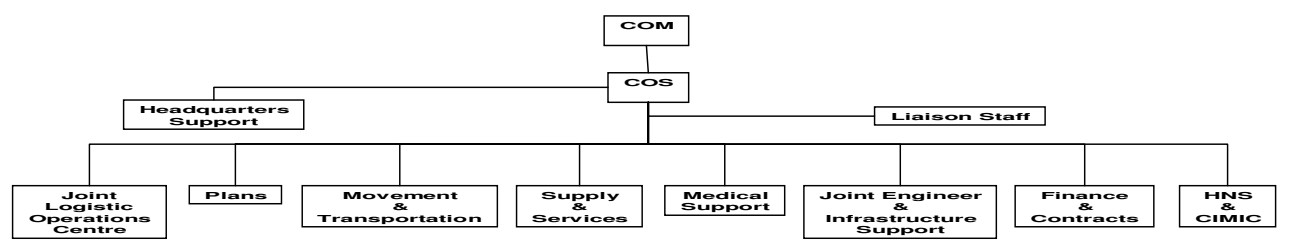

Source: AJP-4.6 (B), 2011, Allied Joint Doctrine for the Joint Logistic Support Group, Study Draft, Brussels, NATO.

\section{Scheme 2: The general structure of the JLSQ HQ}

\section{JLSG Mission in KFOR}

Within KFOR, JLSG was established in January 2010. This was the first time the new logistics concept was used in a NATO operation. Designed for the mission, JLSG had to provide and improve logistic support for all KFOR forces in Kosovo. In order for this to be achieved, an organisation was set up involving the implementation of the tasks of reception, merging of soldiers and equipment, onward movement to the area of operation, redeployment of forces from the area of operation, general engineering and medical support, monitoring internal transport and movement, contracting and property management.

JLSG structure in KFOR comprises the following components: - Commander Command - Unit for reception, merge of soldiers and equipment and onward movement to the area of operations (RSOM) - Supply unit - Transportation unit - Engineering unit for general support and the removal of explosive devices 


\section{JLSG \\ Structure KFOR JLSG HQ}

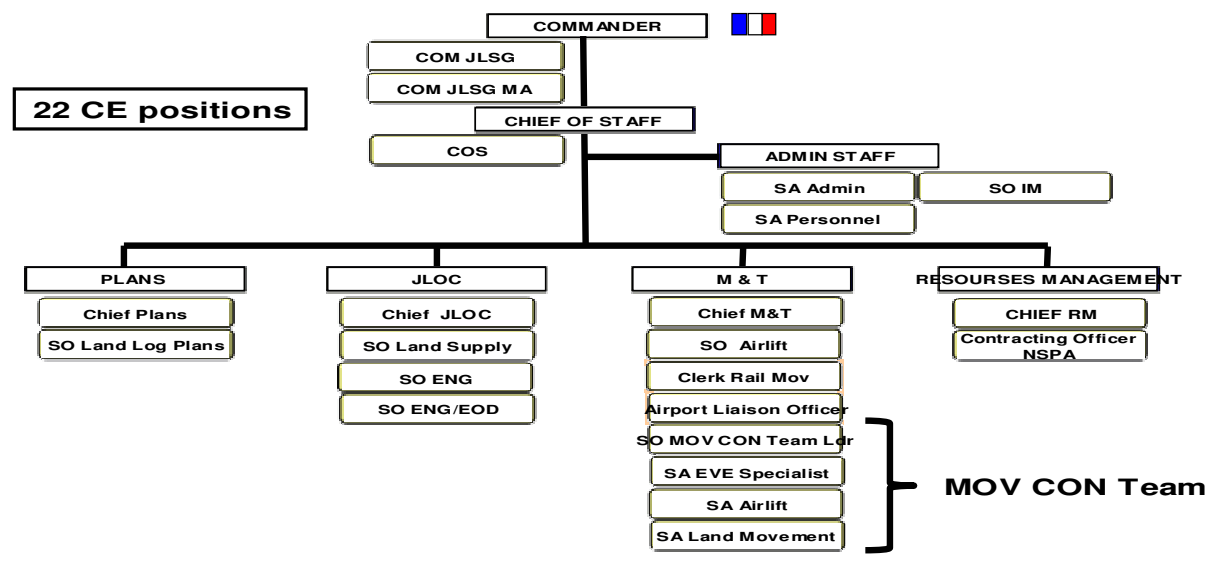

Source: AJP-4.6 (B), 2011, Allied Joint Doctrine for the Joint Logistic Support Group, Study Draft, Brussels, NATO.

\section{Scheme 3: The JLSG structure in KFOR operation}

JLSG in Resolute Support Mission

NATO and troop-contributing nations will have a collective responsibility in supporting the Resolute Support (RS) mission. This support will be provided by national logistic capacities, multinational logistics agreements, commercial contractors and/or host nation support. In order to meet the logistical challenges in the mission, NATO will establish a modified JLSG at the level of operations. The basic idea is to coordinate and synchronise logistics solutions with different national contingents and other entities. JLSG will operate until the end of the RS through all phases of operations, and with strong abilities planned for the implementation of this mission only.

It is important to say that the redeployment of ISAF forces will continue in the RS; therefore, one of JLSG tasks will be the coordination of ISAF redeployment with NATO and troop-contributing nations (TCNs), the host nation and neighbouring countries with the main aim of creating the conditions and standards for effective, efficient and time-feasible redeployment. Capabilities developed through JLSG 
will be adjusted to meet the changes in the requirements for the mission. JLSG organisation will require the appropriate structure of command and control (C2), which should facilitate the coordination and implementation of logistics support. One of the JLSG capabilities is to ensure a Recognised Logistic Picture (RLP) giving the RS Commander visibility over key logistic resources. The JLSG structure must ensure the necessary expertise in contracting services in the area of operations. Infrastructure and medical support are also a part of the capabilities that JLSG develops through all phases of the operation.

In order to facilitate implementation of the above logistics tasks, TCNs will seek the transfer of the logistics C2 authority and capabilities to JLSG. Should logistic units be assigned to JLSG, its functions will be developed in the form of a special command.

The general structure of JLSG in RS was envisioned as a staff element and operates within the CJ4 of joint forces. It should include several common elements:

- Multinational Movement Coordination Centre - with the basic task of movement control, air and ground transport in the area of operations

- Logistics Operations - with the basic task of supply classes of material, real life support and insurance services

- Recognised logistics picture and plans - with the basic task of managing information operations, trends and risks analysis, management of NATO funded equipment and the development of logistics and support plans in the area of operations

- General Engineers in support of units - with the basic task of ensuring the engineering services for the operation and maintenance of all infrastructure (except the airport), the implementation of services for the base, the development of new facilities and infrastructure, freedom of movement on the ground lines of communication and other

- Medical - with the basic task of providing medical supplies - CommunicationInformation Systems - with the basic task of ensuring the internal communication and information capabilities, connectivity with the allocated resources and implementation of Logistic Services Functional Area (LOGFAS) tools

- Contracting - with the basic task of contracting for goods and services in the joint area of operations; establishing of contracting management for joint logistics services, and setting up local contracts. 


\section{Support through contracted solutions}

Support through contracted solutions or support over civilian capacity in the NATO concept of logistic support is defined as use prior to the planned civil contract for the execution of selected logistics support services. The goal is to enable competent business partners providing a portion of logistics support in a way that it supports the execution of the tasks of the Force Commander and that it is focused on optimising the most effective and most efficient use of resources. This type of support is planned in advance improving, in this way, the preplanning activity, as opposed to ad hoc contracting which is widespread in some countries in peacetime and in war. It results in a long-term approach to the scope of logistics support and procurement, which requires detailed negotiations with those contractors whose capabilities for providing logistic support are identified in terms of the scope and standards.

Support through civilian capacity is the multiplier of forces in the operation with particular relevance in the following situations:

- Limitation of the number of persons in the national contingent or in the joint area of operation due to political decisions

- The required capabilities cannot be met by military resources - The required capabilities are not available in the operation yet

- Military capabilities are not available in sufficient numbers for the sustainability of operations - Military capabilities are required for other missions

- The use of local contractors supports the plan of Civil-Military Cooperation (CIMIC)

- The use of contractors (civilian resources and local labour) for certain activities in a given time can be cost-effective

- There is a need for continuing operations and operating experience that cannot be secured using military personnel on a rotating basis

Planned support for NATO military operations is based on an approach that determines the logistics requirements whose fulfillment can effectively and efficiently be implemented by civil contracting. Ad-hoc contracting can also be a response to unforeseen requirements that may arise during the operation. However, the planned approach has greater potential for exploitation of military 
and civilian capabilities in relation to operational effectiveness and reduces costs.

The use of civilian contractors will reduce shortcomings that occur during the process of Force Generation.

Supportthrough the civilian capacity in the RS mission should be considered during the planning process and must take into account compliance with the requirements such as reliability, release of insufficient military resources and their use for more important tasks and acceptability of the operational point of view. Also, it should not be a constraint for the commander's freedom of activity and freedom of movement. These factors must prevail during the process of contracting the major classes of supply (food, fuel, etc.) for the logistic support in the RS.

Supervision of the contracts to be implemented within the operations of RS will be carried out by the contracting department in RS HQ. This department will not have jurisdiction over the commands and other staff elements operating out of Afghanistan.

In order to prevent the outflow of funds to the opposing side, the RS operation will be focused on improving transparency, anti-corruption measures and good practices. The aim is to reduce the risk of corruption, alleviate the damage and enable the economic development of Afghanistan.

The plan is to carry out checks of business and the credibility of civilian contractors. For this purpose, NATO has established a special office for vendor vetting.

Support through contractual solutions in the RS operation must be supported by the NATO agreement with the Government of the Islamic Republic of Afghanistan (GIRoA) to adequately protect the personnel and resources of the participating nations including civilians. This means that NATO civilian employees and contractors must be protected and they must be allowed free movement and safety in performing the required tasks.

The completion of the new legal agreement with GIRoA for the mission after 2014 will enable the setting up of contractual support on time and without major problems. 


\section{The role of NSPA as Contractor Integrator}

The NATO Logistics Committee (LC) analysed the use of contractors in support of NATO-led operations and concluded that it is always useful to appoint a Contract Integrator (CI) in order to complete the plans of military commands and deliver the required contractual solutions. One of the key elements to ensure the success of support through contractors is to rely on their presence in the area of operation. Therefore, an NSPA operates in the ISAF (NATO Support Agency) Senior Representative Office. This office will work with the offices within the subordinate commands to continue its activities in the RS.

In the ISAF operation, other NATO agencies and offices, such as the Theatre Allied Contracting Office (TACO) and the NATO Communication and Information Agency (NCIA), are also involved.

NSPA, as a separate NATO agency, sets a broad framework of management activities that enable the delivery of integrated logistics solutions at lower costs. In the implementation of the ISAF operation, NSPA has gained considerable experience in all areas of contracting support including transportation, real life support, maintenance of military facilities and project management related to infrastructure. Most of the current agreements concluded by the NSPA are flexible and determined in a way that can accept a transition from operating into training, advising and assisting the mission. For the purpose of better synchronisation and harmonisation for the different types of support services in the area of operations, NSPA can be defined as a contract integrator for bases, airports of disembarkation (APoDs) and airports. NSPA will coordinate support of contract services on behalf of all troops in a military camp/base which will result in more efficient use of resources. Moreover, NSPA's ability to make and coordinate contract activities is based on its previous extensive experience in the ISAF operation.

Recognising the opportunities within NSPA, the Supreme Allied Command Europe (SHAPE) has requested the development of consolidated NATO contracts for fuel in the RS. For this purpose, the existing infrastructure for fuel in the ISAF operation was also analysed.

One of the activities in which NSPA can play a significant role in the RS is support of airport operations such as the control, logistics and maintenance functions of 
the airport of disembarkation (APOD), including the runway and parking lots. NSPA ability related to APOD includes the full range of Combined Air Terminal Operations (CATO), such as clearing snow, airport services, handling of aircraft equipment, refueling and maintenance of lighting on the runways.

For the future of the RS mission the expertise that NSPA has, in the support of operating bases and infrastructure, is of key importance. This is primarily related to general engineering support capabilities of maintenance and construction.

Agency expertise in Afghanistan is also connected with the construction and maintenance of the airports and bases, airport control towers, fuel installations, command and control facilities, medical stations, food facilities and outdoor perimeter protection for units.

Of particular interest for the RS mission are NSPA's capabilities related to non traditional engineering activities such as fire protection, rescue, disposal of hazardous materials and other things. In a country where floods are quite frequent, specialist activities that NspA provides and can be planned for the next operation include environmental and hydrological assessment and examinations.

NSPA capabilities related to non traditional engineering activities such as fire protection, rescue, disposal of hazardous materials and alike, represent special interest for the RS mission.

\section{Conclusion}

The implementation of logistics support by relying solely on military capacities has proved extremely difficult to implement in the ISAF operation. In some cases, available resources were not adequate for the specific units' requirements. The RS mission is based on different tasks; therefore, military personnel will be primarily engaged in training, advising, and assisting, as well as force protection. For these reasons it is necessary to obtain other sources of support. One suggested solution is to provide support through civilian capacities. This type of support provides a useful tool for improving the combat support of the units, release of insufficient 
military resources for other priority tasks, overcoming logistic shortcomings and ensuring long-term endurance.

The national logistics solutions prevail in the ISAF operation. Additionally, the NATO joint financing of airports of disembarkation and commands is applied, staffing is not limited, and operations are supported by large logistics organisations. Logistics is independent of the control of the GIRoA.

The logistic support of the RS mission is planned primarily through multinational contracted solutions. The main idea is to establish a multinational logistic approach that should replace national logistics solutions. Management of airport infrastructure and maintenance of the equipment will be assumed by GIRoA. In order to coordinate logistics functions, the plan is to establish a JLSG as capabilities integrator. JLSG will not have units under its command. It will be recognised as a staff element. Therefore, the RS operation requires the transition of logistics support.

\section{References}

\section{Official publications}

AJP-4 (B), 2011, NATO Allied Joint Logistic Doctrine, Brussels, NATO

AJP-4.6 (B), 2011, Allied Joint Doctrine for the Joint Logistic Support Group, Study Draft, Brussels, NATO

AJP-4.9 (A), 2013, Modes of Multinational Logistic Support, Edition A Version 1, Brussels, NATO

AJP-4.5 (B), 2013, Allied Host Nation Support Doctrine \& Procedure, Brussels, NATO

MC 336/3, 2012, NATO Principles for Movement and Transportation, Brussels, NATO

MC 334/2, 2012, NATO Principles for Host Nation Support, Brussels, NATO

MC 133, 2011, NATO Operations Planning, Brussels, NATO

MC 0567/1, Procedure for the Acceptance of troop Contributions to NATO-Led Operations from Non-NATO Nations

BI-SC Conceptual Framework for Alliance Operations Interim Version, 2012, Mons, NATO

ACO Directive (AD) 45-3, 2011, ACO Crisis Establishments (CE) Management, Mons, NATO

SHAPE Directive for the Support Planning and Coodination for ISAF Force Redeployment, Rev. 2, 2013, Mons, NATO 
ACO Directive 60-80, 1994, Property Accounting and Control, Mons, NATO

ACO Directive 80-100, 2013, Redeployment, Mons, NATO

ACO Directive 55-1, 2006, Motor Transport Management, Mons, NATO

BI-SC, 2008, Stock Planning Guidance, Brussels, NATO

PD, 2013, Adapting the Existing Afghan National Army Trust Fund Arrangements, Kabul, GIRoA

NATO Logistic Handbook, 2012, Brussels, NATO

C-M 0047, 2012, Charter of the NATO Support Organisation, Brussels, NATO

PO 0242, 2011, Implementation Plan for NATO Reform, Brussels, NATO

PO 0141, 2011, Political Military Framework for Partner Involvement in NATO-led

Operation, Brussels, NATO

C-M 0004, 2007, NATO Policy on Contractor Support Operation, Brussels, NATO

PO 0143, 2010, Final Comprenhensive Approach, Brussels, NATO

AC/305-D, 0015, 2010, 2011-2020 NATO Logistics Vision and Objectives (V\&O), Brussels, NATO

AC/305 (EAPC)D(2012) 0006, 2012, Definition of Collective Logistics, Brussels, NATO

C-M (2001) 44, 2001, NATO Policy on Cooperation in Logistics, Brussels, NATO

EAPC (SNLC) D (2008) 0007, 2007, Guidelines for a Proportional Contribution of Logistics

Capabilities to a Single Rotation of the NATO Response Forces, Brussels, NATO

C-M (2010) 0063, 2010, NATO Policy for Standardization, Brussels, NATO

C-M (2003) 101 INV/MC 319/2, 2003, NATO Principles and Policies for Logistics,

Brussels, NATO

C-M (2000) 0056-REV1/MC 334/2, 2000, NATO Principles and Policies for Host Nation

Supprot, Brussels, NATO

MC 319/2, 2004, NATO Principles and policies for logistics, Brussels, NATO

MC 0526, 2005, Logistic support concept for NRF, Brussels, NATO 